\title{
RETROSPECTIVA DAS ATIVIDADES DO JARDIM BOTÂNICO NA ATUAL ADMINISTRAÇÃO
}

O apoio recebido do IBDF permitiu à atual direção do Jardim Botânico do Rio de Janeiro traçar um programa de atuação, desenvolvido nos meses seguintes à sua posse (set. 1980) e durante todo o ano de 1981.

Inicialmente foi criada a Assessoria de Planejamento, a cargo do Dr. Décio B. Pizzato. Com o objetivo de buscar recursos financeiros junito a Instituições $e$ adequá-los às necessidades do JBRJ, além de coordenar as diversas atividades de pesquisa, do parque floristico e restauração, a Assessoria de Planejamento não só busca interligar os setores do JBRJ; como propiciar o retorno da Instituição ao seu verdadeiro nivel.

Cabe também, à Assessoria de Planejamento, em conjunto com.o Grupo de Coordenação de Pesquisas, a elaboração de Projetos para a área de pesquisa, já apresentados à direção do IBDF, alguns com início previsto para 1982, dos quais merecem destacar: o Projeto Flora do Rio de Janeiro - para fazer o 19 inventário florístico do Estado e a implantação do Laboratório de Análise de Sementes.

Foi reforçado o efetivo de guardas pelo IBDF que, sensivel à situação em que o JBRJ se encontrava, aumentou-o em 30 homens. Atualmente a Segurança, dirigida pelo Dr. Jorge Bloise, conta com 47 homens, trabalhando em dias alternados, dia e noite, em postos fixos, semi-fixos e rondas de bicicletas.

Em maio de 1981 a Assessoria de Comunicação Social iniciou seus trabalhos, com a finalidade de reerguer a imagem do JBRJ. Para isso foi realizado, inicialmente, um trabalho de base que consistiu em divulgar $Q$ Jardim Botânico para a Imprensa, através de seus eventos - cursos, seminários, exposiçóes etc. e datas históricas importantes, venda de coleções, pesquisas e tudo o mais relacionado à Instituição.

$\dot{A}$ Assessoria de Comunicação Social cabe ainda organizar um arquivo com recortes de jornais e revistas, para formar a memória do JBRJ, além de elaborar textos sobre todos os seus setores; pesquisas e atividades; curiosidades botânicas; prédios históricos; acervo cultural e cientifico; estufas; fauna e Flora; atrações turisticas etc., visando ao atendimento de profissionais de Imprensa, visitantes, guias de turismo, estudantes e demais pessoas interessadas.

Durante o ano de 1981 realizaram-se cursos, parte do programa desenvolvido pela atual Direção, cumprindo os seguintes objetivos: 
- proporcionar aprimoramento aos técnicos da casa:

Curso de Latim para Botânicos, 17 alunos, Prof. Padre Emañuel Amarantes.

- transmitir conhecimento aos estudantes:

1. I Curso Básico de Botânica, 13 alunos, Prof. Hilda Manhã Ferreira, Maria Alice Barroso e Catarina Coutinho.

2. I Curso Básico de Anatomia Vegetal, 13 alunos, Prof. Honório Monteiro Netto e Cecília Gonçalves Costa.

- despertar o interesse e o respeito pela Natureza, além de aproximar a comunidade do JBRJ:

1. I, II, III, IV, V, VI e VII Cursos de Jardinagem e Paisagismo, num total de 131 alunos, Prof. Esther Daemon.

Foto: Mario Silva

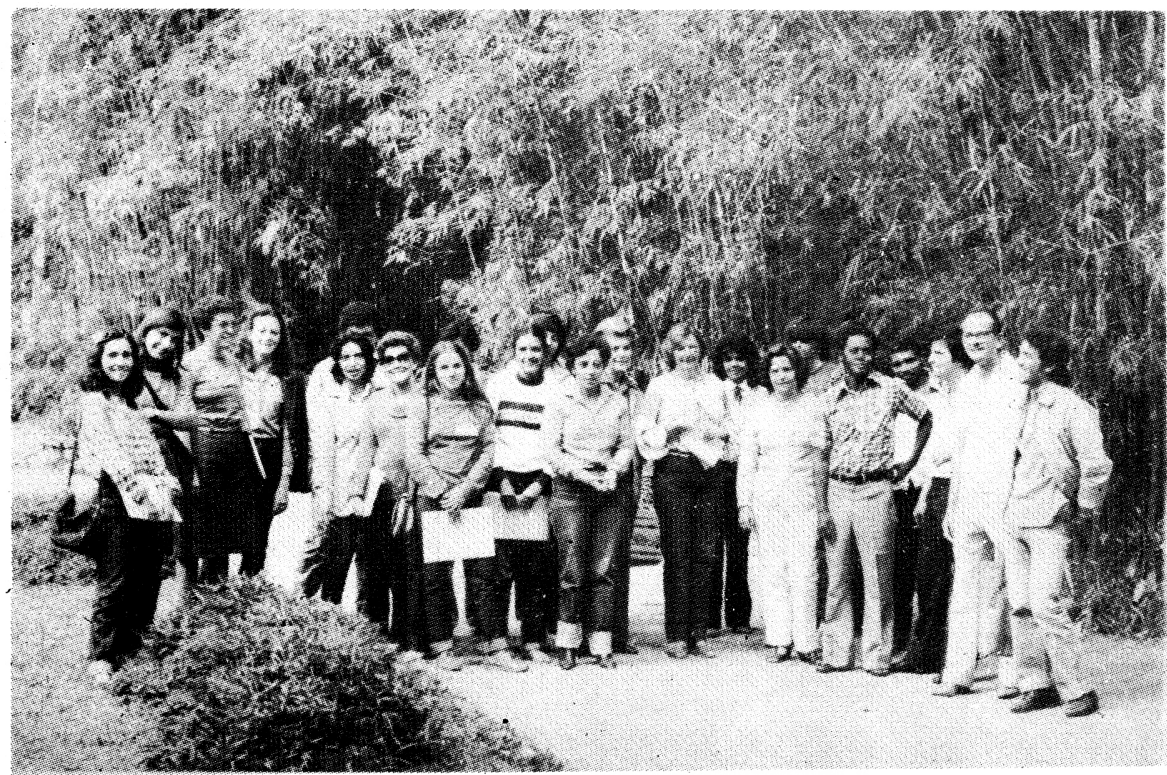

II Curso de Jardinagem e Paisagismo.

2. I Curso de Jardinagem de Interior, 26 alunos, Prof. D. Alzira Cabral e D. Hilda Manhã Ferreira.

Os cursos foram coordenados pelo Museu Botânico Kuhlmann e pelo Grupo de Coordenação de Pesquisas, do JBRJ, e as atividades administrativas foram executadas na Diretoria, por Paulo Roberto Pires Martins. 
Seminários mensais realizaram-se no auditório da Botânica Sistemática, com expositores da casa e de outras Instituições, visando a promover um maior intercâmbio de informações entre os participantes, e expor as pesquisas cientificas que se desenvolvem no JBRJ.

Referente ao funcionalismo do Jardim Botânico, dois acontecimentos marcantes ocorreram em 1981, conforme dados do Núcleo Administrativo, sob a chefia de Carlos Alfaia:

- a Ascensão Funcional, que veio permitir aos funcionários a ascensão dentro da carreira pública, aproveitando seu grau de escolaridade. As provas seletivas foram feitas em novembro e em dezembro o IBDF publicou, em boletim, a lista dos aprovados.

Foram beneficiados 14 funcionários do JBRJ.

- a inclusão de 9 botânicos do JBRJ no Plano de Classificação de Cargos, de acordo com o Decreto - Lei no 1874/81 e Instituição Normativa no 127 do DASP, de 30/9/81.

Os botânicos estavam numa tabela extinta da CLT e eram os únicos não incluidos no último Plano de Classificação de Cargos, de 1974.

Relacionamos abaixo algumas atividades do JBRJ, no decorrer do ano de 1981, conforme indicação dos chefes de cada setor do JBRJ, a quem creditamos a colaboração:

janeiro

- 12 de janeiro: Assinatura do contrato de reconstrução e restauração do prédio da Administração Central do Jardim Botânico.

Assinaram: representando o IBDF, Dr. Ivan Fernandes Barros, Diretor do Jardim Botânico do Rio de Janeiro e Miguel Angel Lahera Alonso, pela Eletro-Mecanave Projetos e Montagens Ltda.

O IBDF reconheceu a importância da área do JBRJ e, após visita do Presidente João Baptista Figueiredo ao Jardim Botânico (fev. 1980), foi possivel aliar recursos do IBDF, SEPLAN e SPHAN/PRÓ-MEMÓRIA, para recuperar os prédios do JBRJ.

O projeto á assinado por Dr. Carlos Fernando de Moura Delphim, que chefia a equipe do Grupo de Restauração e representou o IBDF na fiscalização da obra.

O Instituto do Patrimônio Histórico e Artistico Nacional - IPHAN orientou tecnicamente nas obras, que eram solicitadas há mais de 50 anos.

- de 24 de janeiro a 02 de fevereiro: O JBRJ foi representado por dois de seus pesquisadores - Dr. Armando de Mattos Filho e Dra. Graziela Maciel Barroso, no XXXI Congresso Brasileiro de Botânica, promovido pela Sociedade Botânica do Brasil, em Terezina, Piaui. 
março

- de 9 a 20 de março: Dr. Armando de Mattos Filho e Dr. Carlos Toledo Rizzini, pesquisadores do JBRJ, excursionaram aos Estados de Alagoas e Sergipe, para coletar material botânico, amostras de madeira para o acervo da Xiloteca, cactáceas para a coleção do Jardim Botânico e exemplares de Melocactus, para complementar pesquisa em andamento.

- 25 de março: Comemorando os 160 anos da Independência grega, o Cônsul da Grécia, Anastacios Kriekoukis, plantou uma oliveira no parque floristico do JBRJ.

abril

- 9 de abril: $O$ cientista Moshe Rivlin, presidente mundial da Karen Kayement Leisrael, entidade internacional de defesa da Ecologia, doou ao JBRJ 12 mudas de Pinus alipensis e plantou uma das mudas no Parque Floristico.

- 15 a 27 de abril: Dr. Armando de Mattos Filho e Dr. Carlos Toledo Rizzini participaram de excursão a Minas Gerais e Bahia, para coletar material botânico para pesquisas.

- ainda no mês de abril, Dr. Ivan Fernandes Barros, Diretor do Jardim Botânico do Rio de Janeiro, participou como conselheiro da reunião do Conselho Nacional de Valorização dos Parques, realizada no Parque Nacional das Emas, em Goiás.

Foto: Mario Silva

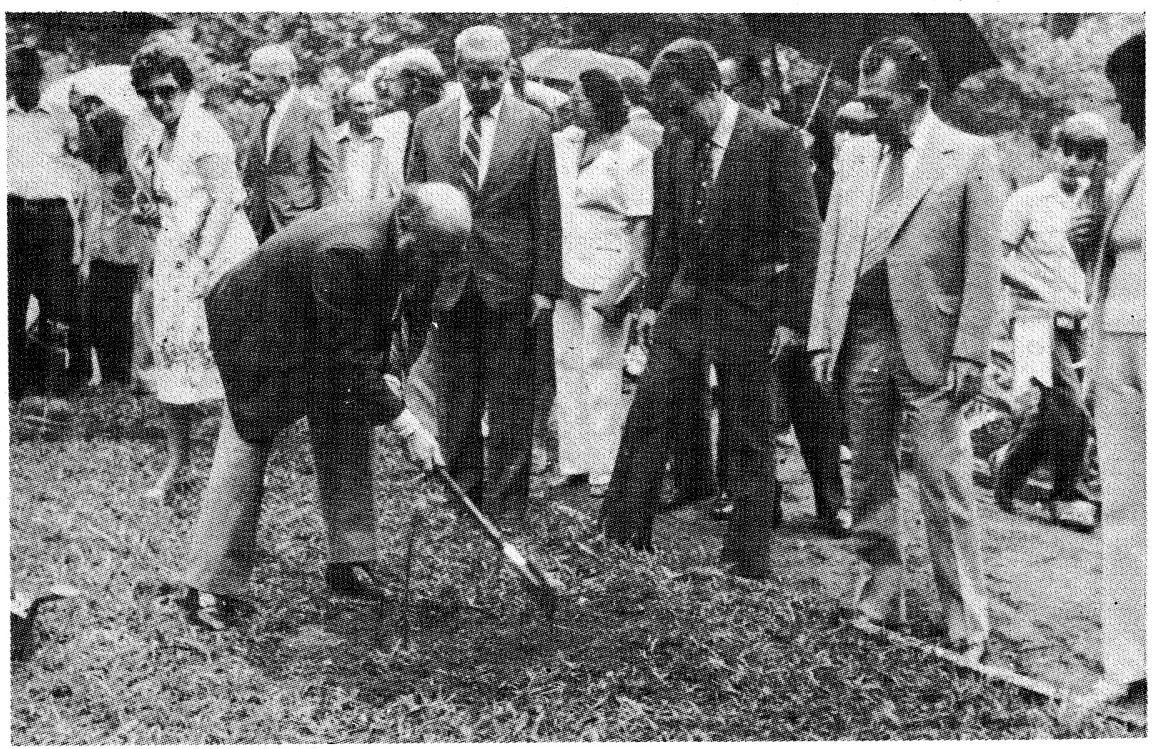

Sr. Moshe Rivlin. plantando uma muda de Pinus alipensis no JBRJ. 
- realizou-se a exposição da Flor de Maio, uma tradição no JBRJ, que atrai muitos visitantes ao Jardim, ansiosos por admirar a variedade de cores e a beleza das flores.

A realização da Exposição deve-se ao trabalho do Grupo de Aplicação Florística - GAF, chefiado pela Dra. Carmem Lúcia Falcão Ichaso e à dedicação de Manoel Pedro Allemando Coelho e Walter da Costa Garcia.

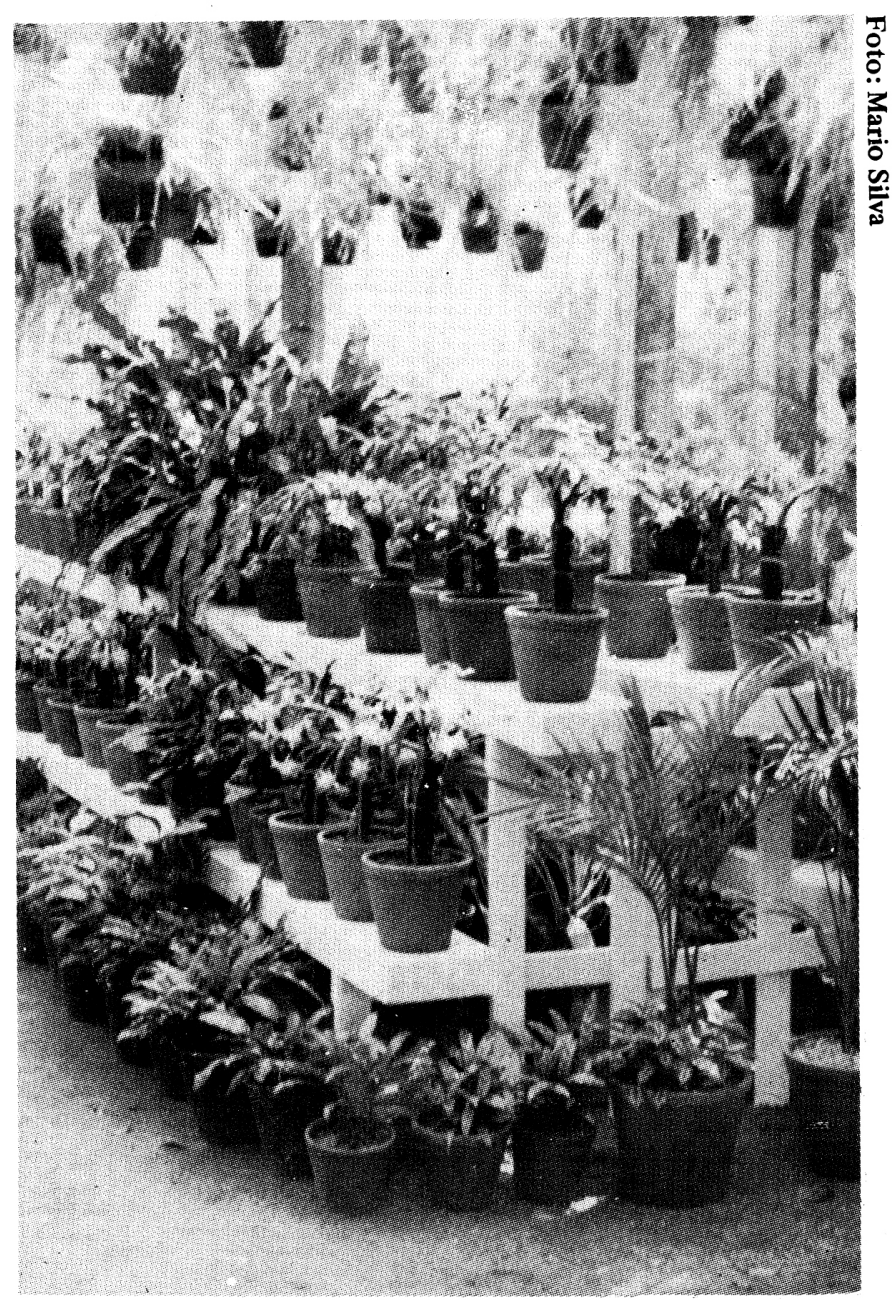

Exposição de Flor de Maio. 
junho

- 13 de junho: O JBRJ comemorou 173 anos e foi homenageado pelo Museu Botânico Kuhlmann, com a 16! Exposição Temporária, que mostrou Madeiras Brasileiras (com o apoio do setor de Anatomia Vegetal) e a Palma Mater, a palmeira real que originou todas as outras, hoje espalhadas pelo Brasil.

Cabe ressaltar a acolhida de todos os órgãos da Imprensa - rádio, televisão, jornal e revista - que divulgaram amplamente o aniversário do Jardim Botânico do Rio de Janeiro.

agosto

- término das obras do prédio da Administração Central. Parte da $1^{a}$ Etapa do Plano de Obrás, elaborado pelo Grupo de Restauração, as obras de restauração do prédio foram custeadas com recursos do IBDF (Cr\$3.735.295,00) e de SPHAN/PRO-MEMÓRIA (CR\$14.505.857,00).

setembro

- 2 a 12 de setembro: Dra. Elsie Franklin Guimarães, Chefe do Grupo de Coordenação de Pesquisas do JBRJ, e Luciana Mautone, Bióloga do IBDF/FAEPE, excursionaram à Reserva Biológica de Poço das Antas, em Silva Jardim, Estado do Rio de Janeiro. A excursão é parte do Projeto de Recuperação da Flora e da Fauna da Reserva, trabalho que vem sendo desenvolvido em conjunto pelo IBDF - Delegacia Estadual do Rio de Janeiro e Jardim Botânico do Rio de Janeiro.

outubro

- 20 de outubro: Dr. Ivan Fernandes Barros, Diretor do Jardim Botânico do Rio de Janeiro, participou como conferencista, no Conselho de Turismo, da Confederação Nacional do .Comércio, falando sobre A Influência do Jardim Botânico no Turismo do Rio. $\dot{A}$. Conferência seguiram-se debate e a exibição de filmes sobre o Jardim Botânico.

- visita à Reserva Florestal do Grajaú para avaliação e coleta de plantas, visando à recomposição vegetal da Reserva, trabalho em conjunto do JBRJ e Secretaria de Agricultura.

Participaram: Dra. Elsie Franklin Guimarães e Luciana Mautone, do Jardim Botânico.

novembro

- 22 a 25 de novembro: Reuniram-se no Jardim Botânico do Rio representantes das Delegacias Estaduais do IBDF (regiões Sul e Sudeste) e da Coordenadoria de Orçamento e Finanças (Brasilia), para discutirem o Plano Operativo 1982, de modo a adequar os recursos disponiveis às necessidades de cada setor. 
Dr. Décio Baptista Pizzato, Assessor de Planejamento, representou o JBRJ. O Diretor do Jardim Botânico, Dr. Ivan Fernandes Barros, fez a abertura da reunião e falou no encerramento, enfatizando a importância de encontros dessa natureza, que permitem troca de experiências e um maior entrosamento entre setores do IBDF.

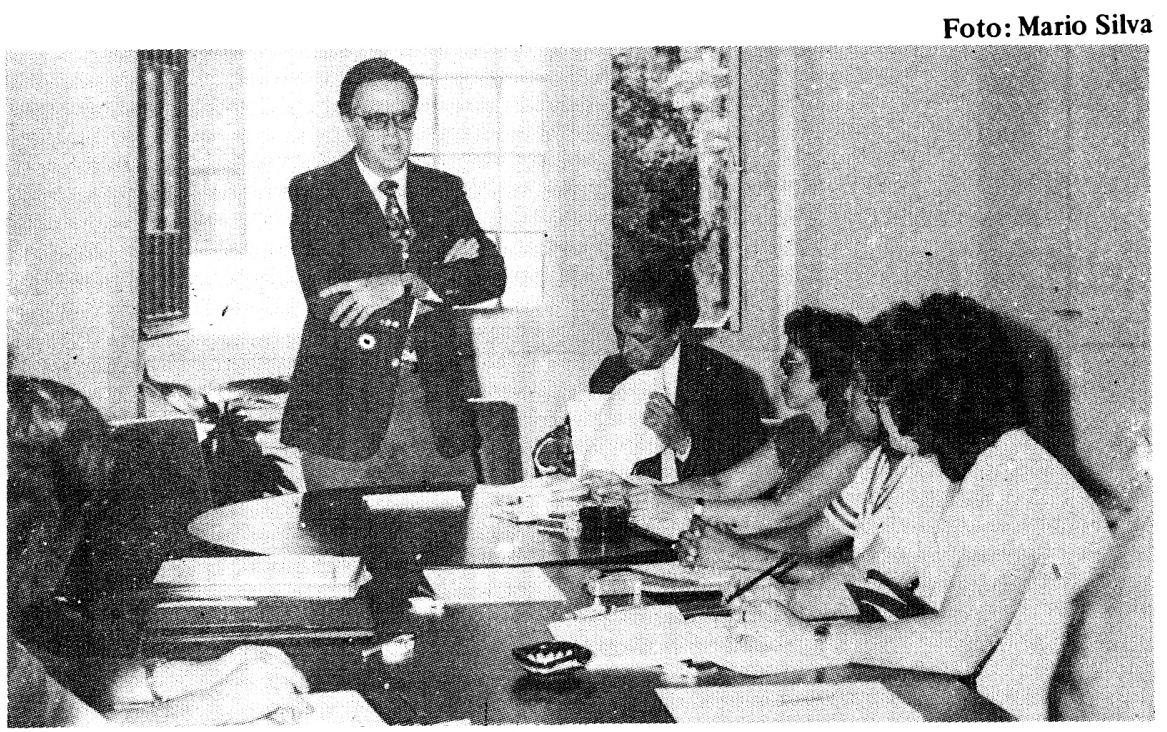

Reunião do Plano Operativo para 1982 do I.B.D.F. Região Sul e Sudeste

Dr. Ivan Fernandes Barros, Diretor do JBRJ, discursando na abertura da Reunião dos representantes do IBDF, regiōes Sul e Sudeste, para estudos do Plano Operativo 1982.

dezembro

- 4 de dezembro:O editor Gilberto Huber - AGGS Indústrias Gráficas S.A. tornou possivel a reedição do livro de J. Barbosa Rodrigues, STRUCTURE DES ORCHIDEES, uma obra ainda atual, apesar de passados 100 anos de sua edição. O jantar comemorativo do lançamento do livro, oferecido pelo Editor, realizou-se no JBRJ, inaugurando-se um espaço cultural nesta Instituição de ciência.

Dr. Ivan Fernandes Barros, Diretor do Jardim Botânico, escreveu o prefácio, enfocando o valor da reedição da obra.

Outros acontecimentos e atividades que se destacaram no Jardim Botânico:

- o levantamento que o setor de Citomorfologia fez sobre Plantas Tóxicas Ornamentais, que mereceu ampla divulgação da Imprensa e de publicações técnicas. Diversas entidades solicitaram cópias do trabalho, dentre essas: Museu de História Natural da Universidade Federal de Minas Gerais, em Belo Horizonte; Instituto Nacional de Tecnologia, do Ministério da Indústria e Comércio; Fundação Severino Sombra, em Vassouras; 
Fundação Zoobotânica do Rio Grande do Sul, em Porto Alegre; Centro de Operações Especiais do Exército - RJ etc.

$O$ setor desenvolve pesquisa sobre oleaginosas e, em conjunto com a Universidade Rural, em Itaguai, estuda as plantas tóxicas para o gado.

$O$ atendimento à Imprensa, sempre que necessárias as informações técnicas, foi feito por Dr. Honório Monteiro Netto, da Citomorfologia.

- os 94 estudos e pesquisas que se desenvolvem na área de Botânica Sistemática, pelos pesquisadores do IBDF/JBRJ, Bolsistas do CNPq., Consulentes e Orientados.

o trabalho sobre Estrutura de Madeiras Brasileiras de Angiospermas Dicotiledôneas (XXIV), concluido pelo setor de Anatomia Vegetal em setembro de 1981, além da identificação de madeiras que o setor realizou para diversos consulentes nacionais e estrangeiros.

- o atendimento a consulentes nacionais e estrangeiros, na Biblioteca Barbosa Rodrigues, destacando-se:

Padre Grange André, Sorbonne - Paris; Jairo Mello, Associação Médica Homeopática - Argentina; Fritz Zehmann, Universidade de Berlim; Jeremy J. Strudwick, Jardim Botânico de Kew-Inglaterra; Brian Boom e Scorr Shori, Jardim Botânico de N. York; Eizo Saito, Universidade Senshu - Japão; K. Y. Wyman, Jardim Botânico da África do Sul e outros.

A Biblioteca Barbosa Rodrigues passou a integrar o Programa de Comutação Bibliográfica (COMUT), que possibilita aos seus usuários a obtenção de cópias de documentos, independentemente de sua localização, obtidos de outras Instituições integrantes do sistema.

- a preservaçã், manutenção e recuperação de espécies botânicas do Parque Floristico, a cargo do Grupo de Aplicação Floristica - GAF, que coordenou também a venda de mudas de plantas, além de atender e dar assessoria aos artigos técnicos para a Imprensa.

a venda da coleção (6 volumes - CR $\$ 12.000,00$ ) Dicionário Pio Correa, cuja divulgação pela Imprensa permitiu a venda de 165 coleções, nos primeiros 4 meses, aumentando em 2459\% o item da receita "Publicações e Impressos".

Em dezembro de 1981, a venda já ultrapassara as 200 coleções.

- as Exposições Temporárias do Museu Botânico Kuhlmann - 4 ao ano, realizadas nas datas de nascimento e morte do Dr. Kuhlmann; na Semana da Ärvore e no aniversário do Jardim Botânico.

- a recuperação de obras de arte, do chafariz inglês do século XIX, fontes e bebedouros; a reconstrução do telhado do Portão Principal; a reforma das 
Aráceas (GAF), Bromeliáceas e Convolvuláceas (Botânica Sistemática); o Projeto realizado pelo Grupo de Restauração para o galpão de secagem de sementes, que integra o Projeto de Implantação do Laboratório de Análise de Sementes; a reforma das estufas do Cactário; o levantamento dos nomes vulgares das espécies do Parque Floristico, já elaborado das Letras A a M; a instalação das cabines para os guardas; a programação visual para guiar o visitante nas dependências do Jardim.

O trabalho desenvolvido pela atual Direção pode ser avaliado pelo crescente indice de visitação do Jardim Botânico, cujo controle é feito pelo setor de Arrecadação e apoiado pelo trabalho de Cibele Honorato da Silva.

\begin{tabular}{|l|c|c|}
\hline \multirow{2}{*}{ VISITANTES - QUANTIDADE } \\
\hline \multirow{2}{*}{ A N N $\mathrm{O} S$} \\
\cline { 2 - 3 } & 1980 & 198.1 \\
\hline \multirow{2}{*}{ JANEIRO } & 26.127 & 34.328 \\
\hline FEVEREIRO & 22.913 & 27.998 \\
\hline MARÇO & 22.339 & 20.740 \\
\hline ABRIL & 16.295 & 28.081 \\
\hline MAIO & 27.321 & 36.777 \\
\hline JUNHO & 18.041 & 26.159 \\
\hline JULHO & 22.159 & 30.393 \\
\hline AGOSTO & 17.630 & 28.848 \\
\hline SETEMBRO & 16.531 & 32.887 \\
\hline OUTUBRO & 21.580 & 31.135 \\
\hline NOVEMBRO & 24.354 & 26.376 \\
\hline DEZEMBRO & 21.833 & 19.093 \\
\hline
\end{tabular}

O Jardim Botânico do Rio de Janeiro mantém um intercâmbio constante com Instituições nacionais e estrangeiras, realizando permutas de publicações, sementes, amostras de madeiras, mudas, material do Herbário e informações técnicas, numa demonstração da importância deste centro de ciência, desde 1825 dedicado ao estudo da Botânica.

Lúcig Stela de Moura Gonçalves Assessoria de Comunicação Social dezembro/1981 
Foto: Mario Silva

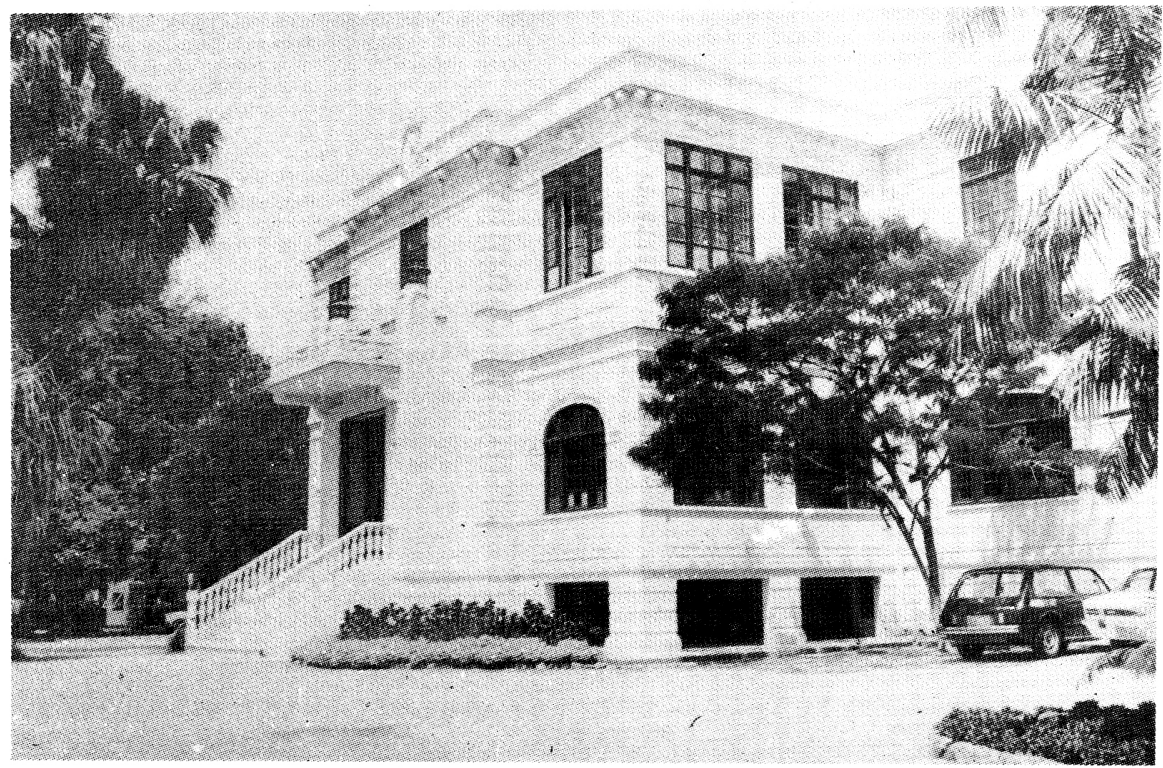

Prédio da Administração Central, restaurado em 19/08/81, na administração do Dr. Ivan Fernandes Barros. 